\title{
The Influences of Landcover structure on surface urban heat islands: A case study of Ho Chi Minh, Vietnam
}

\author{
Ha Thu Thi Le ${ }^{1,}$, , Nhat Dac Doan ${ }^{1}$, Lam Thi Huynh ${ }^{1}$, Thuy Thanh Thi Nguyen ${ }^{1}$, Hiep \\ Ngoc Thi Nguyen ${ }^{1}$, Thuy Thanh Thi Luu ${ }^{1}$, Chinh Cong Thi Vo르 ${ }^{2}$ Nghi Thanh Le ${ }^{1}$ \\ ${ }^{1}$ Faculty of Geomatics and Land Administration, Hanoi University of Mining and Geology, Vietnam \\ ${ }_{2}^{2}$ Publishing Office, Hanoi University of Mining and Geology Vietnam
}

\begin{abstract}
ARTICLE INFO
ABSTRACT

Article history:

Received 15th Jan. 2020

Revised $20^{\text {th }}$ Mar. 2020

Accepted 29th Apr. 2020

Keywords:

Land cover structure,

Remote sensing and GIS,

Surface urban heat islands.

Urbanization is taking place at an unprecedented rate around the world, particularly in Vietnam. One of the key impacts of rapid urbanization on the environment is the effect of urban heat island (UHI). Understanding the effects of landscape pattern on UHI is crucial for improving the ecology and sustainability of cities. This study investigated how landscape composition and configuration would affect UHI in the District 7, Ho Chi Minh City of Vietnam, based on the analysis of land surface temperature (LST) in relation to the percentage of vegetation, impervious, and water surface. Landsat 8 OLI satellite images acquired on February 14th, 2017 was used to estimate the LST from the thermal channel, while the percentage of vegetation, impervious, and water surface were extracted from multi - spectral channels. Our results indicate that there is a significant difference in LST among the wards in the study area. Impervious surfaces contribute the most to UHI, followed by bare soil, vegetative cover, and water. The research results also show that the structure of urban coverings should reach: $50 \%$ of impermeable surfaces and bare land, the remaining 50\% are water and vegetation. These results are useful for understanding urban ecology as well as land use planning to minimize the potential environmental impacts of urbanization.
\end{abstract}

${ }^{*}$ Corresponding author

E - mail: lethithuha@humg.edu.vn

DOI: 10.46326/JMES.2020.61(2).09 


\title{
Đánh giá vai trò của cơ cấu lớp phủ bề mặt đô thị trong việc giảm hiệu ứng đảo nhiệt đô thị áp dụng cho khu vực Thành phố Hồ Chí Minh, Việt Nam
}

\author{
Lê Thị Thu Hà ${ }^{*}$, Đoàn Đắc Nhất ${ }^{1}$, Huỳnh Thị Lam ${ }^{1}$, Nguyễn Thị Thanh Thúy ${ }^{1}$, \\ Nguyễn Thị Ngọc Hiệp ${ }^{1}$, Lưu Thị Thanh Thủy ${ }^{1}$, Võ Thị Công Chính ${ }^{2}$, Lê Thanh Nghị ${ }^{1}$ \\ ${ }^{1}$ Khoa Trắc địa - Bản đồ và Quản lý đất đai, Trường Đại học Mỏ - Đị chất, Việt Nam \\ 2 Phòng Xuất bản, Trường Đại học Mỏ - Địa chất, Việt Nam
}

THÔNG TIN BÀI BÁO T TÓM TẮT

Quá trình:

Nhận bài 15/01/2020

Sưa xong 20/3/2020

Chấp nhận đăng 29/4/2020

Tù khóa:

Cơ cấu lớp phủ bề mặt đô

thị,

Công nghệ viễn thám và

GIS,

Hiệu ứng đảo nhiệt đô thị (UHI).
Đô thị hóa đang diễn ra với tốc độ chưa tùng thấy trên toàn thế giới, trong đó có Việt Nam. Đảo nhiệt đô thị (UHI) là một trong nhũng hậu quả chính của quá trình đô thị hóa. Nghiên cúu này đã điều tra và đánh giá vai trò của cơ cấu lớp phủ bề mặt đô thi sẽ ảnh hướng đến UHI ở khu vực đô thi quận 7 , thành phố Hồ Chí Minh, dựa trên việc phân tích nhiệt độ bề mặt đất (LST) liên quan đến tỷ lệ phần trăm thảm thực vẫt, tỷ lẹ không thấm nước, tỷ lệ lớp phủ mặt nước và tỷ lệ lớp phủ đất trống. Ánh vệ tinh Landsat 8 OLI thu được vào ngày 14 tháng 2 năm 2017 đã được sử dưng để ước tính đồng thò̀i LST từ kênh nhiệt, còn tỷ lệ thảm thực vật, tỷ lẹ phần trăm không thấm nước, tỷ lệ lớp phủ mặt nước và đất trống được chiết xuất tù̀ các kênh đa phổ. Kết quả nghiên cứu đã chỉ ra rằng, có sự khác biệt đáng kể về LST giũ̃a các phường trong khu vực nghiên cứu. Bề mặt khồng thấm đóng góp lớn nhất dẫn đên hiên tượng UHI, tiếp theo là đất trống, lớp phủ thực vật và mặt nước. Nhũng kết quả nghiên cúu này rất hữu ích để hiểu về sinh thái đô thị cũng như quy hoạch sử dụng đất để giảm thiểu các tác động tiềm ẩn đển mồi trường của quá trình đô thị hóa.

\section{Mở đầu}

Hiện tượng đảo nhiệt đô thị (UHI - Urban Heat Island) được hiểu là hiện tượng mà tại cùng thời điểm, nhiệt độ trung bình ở khu vực phát triển đô thị với nhiều công trình nhân tạo cao hơn ở khu

\footnotetext{
*Tác giả liên hệ

E-mail: lethithuha@humg. edu.vn

DOI: 10.46326/JMES.2020.61(2).09
}

vực công viên và nông thôn, nơi có môi trường tự nhiên xung quanh, sự tăng nhiệt độ cục bộ này tạo nên một khu vực trung tâm như một "ốc đảo" có nhiệt độ cao hơn các nơi khác (EPA, 2008). Hiện tượng đảo nhiệt đô thị hiện đang là một trong những chủ đề quan trọng trong nghiên cứu khí hậu và môi trường đô thị. Hơn $50 \%$ dân số trên thế giới hiện đang sống tại các khu vực đô thị và con số này sẽ tiếp tục tăng lên, đặc biệt tại các quốc gia đang phát triển (United Nations, 2008). Một 
trong những hậu quả sinh thái của quá trình đô thị hóa là UHI, dẫn đến nhiệt độ ở khu vực thành thị cao hơn so với khu vực ngoại ô/nông thôn xung quanh. Sự thoải mái của cư dân đô thị bị ảnh hưởng bởi nhiệt độ bề mặt thông qua sự thay đổi của nhiệt độ trong không khí của tầng thấp nhất của bầu khí quyển đô thị (Udhi C. Nugroho, Dede Dirgahayu Domiri, 2015). UHI có thể được đánh giá theo hai cách, theo truyền thống, nó được lấy từ các phép đo nhiệt độ không khí trong các loại hình lớp phủ đô thị. Gần đây, chủ yếu các nghiên cứu về UHI đều dựa trên nhiệt độ bức xạ bề mặt từ các cảm biến từ xa (Voogt, 2002).

Sự phát triển của dữ liệu viễn thám nhiệt cung cấp một giải pháp tốt cho các nghiên cứu muốn quan sát được hiện tượng đảo nhiệt đô thị (Weng, 2009). Các kỹ thuật này có thể theo dõi hiệu quả, giúp định lượng các đặc điểm phân bố của các khu vực đảo nhiệt đô thị cũng như các thay đổi định kỳ và không định kỳ trong môi trường nhiệt đô thị (Grimmond, 2007). Công nghệ viễn thám đã trở thành một phương pháp quan trọng để theo dõi và nghiên cứu nhiệt độ đô thị (Voogt và Oke, 2003). Các nghiên cứu ban đầu về nhiệt đã sử dụng dữ liệu ảnh vệ tinh có độ phân giải vừa phải (MODIS) và máy đo phóng xạ độ phân giải rất cao (AVHRR), để mô tả sự phân bố chung của nhiệt bề mặt đất (Schwarz và nnk., 2011; Tran và nnk., 2006). Sau đó, các dữ liệu cảm biến có độ phân giải trung bình như Landsat và ASTER đã được sử dụng rộng rãi để nghiên cứu các khu vực xảy ra UHI. Ví dụ, Chen và các cộng sự (2006) đã sử dụng ảnh vệ tinh Landsat TM để đánh giá sự thay đổi độ che phủ của đất và đặc điểm phân phối của UHI ở khu vực đồng bằng sông Châu Giang trong quá trình đô thị hóa nhanh chóng. Kato và Yamaguchi, (2005) đã phân tích sự phát triển của đảo nhiệt đô thị ở Nagoya, Nhật Bản, nghiên cứu đã sử dụng dũ liệu ASTER và Landsat ETM +, chủ yếu bằng cách khám phá sự phát thải nhiệt của con người và bức xạ nhiệt tự nhiên. Các nghiên cứu liên quan khác bao gồm (Liu và nnk., 2016; Weng và nnk., 2004; Yuan và Bauer, 2007).

Loại hình lớp phủ mặt đất đóng một vai trò quan trọng trong thay đổi môi trường đô thị (Wang và nnk., 2019). Việc khai thác chính xác và kịp thời các loại che phủ đất là rất quan trọng để giám sát và quản lý môi trường trong các khu vực đô thị. Tuy nhiên, sự tương tác giữa lớp phủ đất và các biến đổi môi trường nhiệt là rất phức tạp
(Buyantuyev và Wu, 2010). Các mô hình và kỹ thuật tiên tiến được yêu cầu để mô tả quá trình này, đặc biệt là đối với các khu vực ngoại thành điển hình. Đặc biệt, việc chuyển đổi từ loại bề mặt đất tự nhiên sang tầng không thấm nước đô thị có thể dẫn đến thay đổi khí hậu khu vực rõ rệt. Môi trường nhiệt đô thị được coi là một biến số nghiên cứu điển hình của nhiều nhà nghiên cứu (Liu và nnk., 2014; Weng và Lu, 2008). Các phân tích chính xác hơn về việc sử dụng đất đô thị đối với sự phân bố nhiệt độ bề mặt đất đô thị (LST - Land Surface Temperature) và phạm vi, cường độ của đảo nhiệt đô thị rất hữu ích để hiểu các cơ chế về nguyên nhân và sự phát triển của các đảo nhiệt đô thị (Wang và nnk., 2019). Sử dụng các kỹ thuật viễn thám để nghiên cứu các biến thể của đảo nhiệt đô thị giữa các loại che phủ đất khác nhau là rất quan trọng để theo dõi chính xác hiện tượng đảo nhiệt đô thị và xác định khách quan về sự thay đổi không gian của các khu vực đảo nhiệt đô thị.

Trong bối cảnh trên, nghiên cứu này đã dựa trên dữ liệu ảnh vệ tinh Landsat 8 OLI để nghiên cứu, trích xuất các thông tin và phân tích sâu hơn về ảnh hưởng của cơ cấu lớp phủ bề mặt đô thị với nhiệt độ bề mặt đô thị và xác định các khu vực xảy ra UHI. Nghiên cứu này sẽ giúp hiểu được cấu trúc lớp phủ bề mặt đô thị phù hợp để có môi trường nhiệt trong đô thị ở khu vực quận 7, TP Hồ Chí Minh. Bên cạnh đó, các tác giả cũng hi vọng kết quả của nghiên cứu sẽ cung cấp hỗ trợ cho các nghiên cứu cơ bản về việc tối ưu hóa quy hoạch cảnh quan đô thị và giảm nhiệt cho đô thị. Do tốc độ đô thị hóa và quá trình chuyển đổi cảnh quan quá nhanh chóng, khu vực quận 7, thành phố Hồ Chí Minh đã trải qua những thay đổi đáng kể về cơ cấu loại hình lớp phủ, do đó dẫn đến một loạt các vấn đề môi trường nhiệt đô thị, trong đó nổi bật lên là hiện tượng đảo nhiệt đô thị.

\section{Khu vực nghiên cứu}

Quận 7 là quận nội thành nằm ở phía Nam thành phố Hồ Chí Minh, từng là một phần của huyện Nhà Bè trước kia (Hình 1). Quận 7 nổi tiếng với khu chế xuất Tân Thuận, công viên giải trí Wonderland và Khu đô thị mới Phú Mỹ Hưng (Khu đô thị Nam Sài Gòn), khu đô thị Cityland Riverside, khu đô thị Nam Phú Villas, khu đô thị Him Lam Kênh Tẻ. Quận 7 có vị trí địa lý chiến lược trong khai thác giao thông thuỷ và bộ, là cửa ngõ phía Nam của thành phố, là cầu nối mở hướng phát 


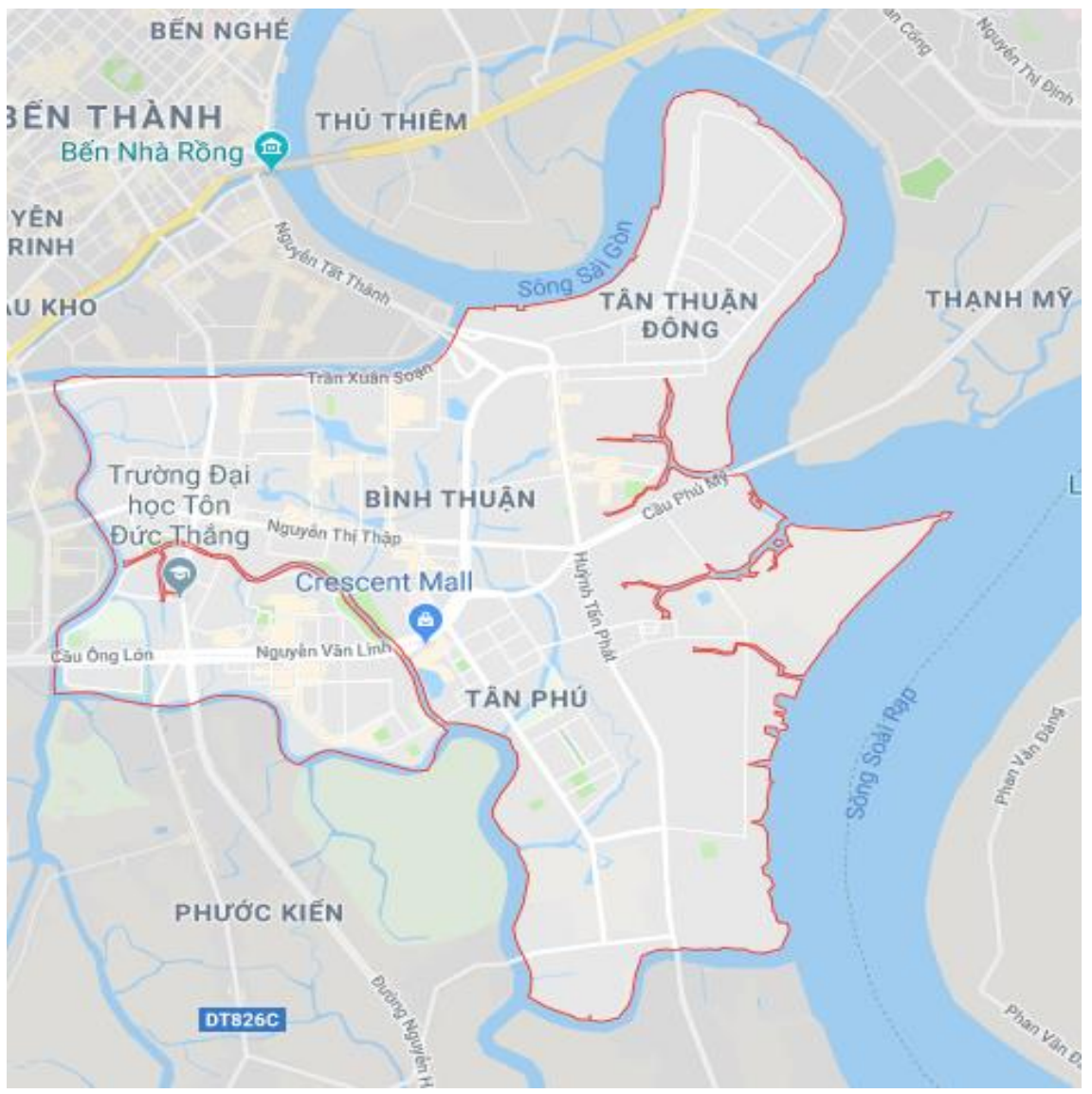

Hình 1. Khu vực nghiên cúu.

triển của thành phố với biển Đông và thế giới. Các trục giao thông lớn đi qua quận 7 bao gồm: xa lộ Bắc Nam, đường cao tốc Nguyễn Văn Linh, sông Sài Gòn bao bọc phía Đông với hệ thống cảng chuyên dụng, trung chuyển hàng hoá đi nước ngoài và ngược lại, rất thuận lợi cho việc phát triển thương mại và vận tải hàng hoá cũng như hành khách đi các vùng lân cận. Với những giá trị đó, quận 7 có điều kiện thu hút đầu tư trong và ngoài nước. Khu chế xuất Tân Thuận trên địa bàn quận là một trong những khu chế xuất lớn và hiệu quả nhất của thành phố.

Như vậy, trong những thập kỷ gần đây, khu vực quận 7 TP Hồ Chí Minh đã chuyển từ một khu vực ven đô thuộc huyện Nhà Bè sang một trung tâm kinh tế theo định hướng công nghiệp, thương mại và dịch vụ có mức độ đô thị hóa cao. Với sự chuyển đổi nhanh chóng của các lớp phủ tự nhiên đô thị thành đất xây dựng (mặt không thấm), hiện tại việc mở rộng đô thị của khu vực này đã gần đạt đến mức bão hòa. Quá trình đô thị hóa cao và nhanh chóng không chỉ gây ra áp lực dân số lớn cho khu vực địa phương mà còn dẫn đến sự gia tăng liên tục của bề mặt đất không thấm nước và sự phân mảnh của đất sinh thái, do đó dẫn đến sự gia tăng liên tục của hiện tượng đảo nhiệt đô thị.

\section{Dữ liệu và phương pháp nghiên cứu}

\subsection{Dũ̃ liệu nghiên cứu}

Dũ liệu ảnh vệ tinh được sử dụng là 01 cảnh ảnh Landsat $8 \mathrm{OLI}$ thu được vào ngày 14 tháng 2 năm 2017, ảnh được lấy từ trang web https://glovis.usgs.gov và đã được xử lý ở mức độ 2 (sản phẩm này đã được cải chính biến dạng do chênh cao địa hình, đã được hiệu chỉnh các thông số khí quyển trong quá trình thu nhận ảnh để có được sản phẩm phổ phản xạ bề mặt đất).

\subsection{Phương pháp nghiên cứu}

\subsubsection{Chiết xuất thông tin nhiệt trên ảnh vệ tinh Landsat}

Nhiệt độ bề mặt (Land Surface Temperature LST) được ước tính thông qua hai bước và dựa theo các công thức được U.S. Geological Survey 
đề xuất đối với ảnh Landsat 8 OLI.

Bước đầu tiên là chuyển các giá trị cấp độ xám về giá trị phản xạ phổ theo công thức sau:

$$
L \lambda=M L \cdot Q c a l+A I
$$

Trong đó: $L \lambda$ là giá trị bức xạ phổ (đơn vị $\left.\mathrm{cW} / \mathrm{m} 2 . \mathrm{sr}^{\wedge} \mathrm{m}\right) ; M_{L}$ là hệ số hiệu chỉnh khuếch đại dành riêng cho kênh ảnh được dùng; $A l$ là hệ số hiệu chỉnh được cộng thêm vào; Qcal à kênh ảnh được dùng để chuyển đổi.

Sau khi hiệu chỉnh bức xạ, kênh ảnh hồng ngoại nhiệt sẽ được sử dụng để tính nhiệt độ độ chói (brightness temperature). Việc xác định nhiệt độ từ giá trị bức xạ của ảnh hồng ngoại nhiệt LANDSAT được thực hiện theo công thức sau:

$$
T_{b}=K 2 /(\ln (K 1 / L \lambda+1))
$$

Trong đó: Tblà nhiệt độ bề mặt do vật thể phát ra (độ $K) . K 1$ và $K 2$ là các hệ số hiệu chỉnh ứng với kênh ảnh được sử dụng để tính toán. Bộ ảnh Landsat 8 có hai kênh ảnh có thể dùng để tính nhiệt độ, kênh 10 và kênh 11 , hai kênh ảnh này được gọi là kênh hồng ngoại nhiệt (Thermal Infrared - TIRS). Vì thiếu các giá trị thực đo để hiệu chỉnh nhiệt độ, nghiên cứu này chỉ sử dụng kênh ảnh 10 để tính nhiệt độ vì khoảng bước sóng kênh 10 hẹp, giúp bức xạ phản xạ lại có độ phân giải cao, nhờ đó mà sự khác biệt nhiệt độ giữa các loại lớp phủ bề mặt được nhận biết rõ ràng. và sau đó, nhiệt độ độ chói có thể được hiệu chỉnh theo LST thông qua độ phát xạ bề mặt theo công thức:

$$
\begin{gathered}
L S T=T /\left(1+\left(\lambda^{*} T / \varrho\right) \operatorname{In} \varepsilon\right) \\
\varrho=\left(h^{*} c\right) / \sigma
\end{gathered}
$$

Trong đó: $\lambda$ là bước sóng của bức xạ phát ra, là hằng số Boltzmann; $h$ là hằng số Planck; $C$ là vận tốc ánh sáng.

\subsubsection{Phương pháp phân loại lớp phủ trên ảnh vệ tinh}

Để chiết tách các thông tin lớp phủ bề mặt đô thị tại quận 7, TP Hồ Chí Minh, nghiên cứu này đã sử dụng phương pháp phân loại pixel - based với thuật toán phân loại xác suất cực đại Maximum likelihood (Li và nnk., 2016; Otukei và Blaschke, 2010). Bản chất của phương pháp này là nếu giá trị quan sát của một mẫu được chọn của một lớp chưa biết có giá trị tương tự như bộ mẫu (huấn luyện) của một lớp đã được biết đến, thì mẫu đó sẽ được phân loại vào lớp đó. Theo các đặc điểm cụ thể của lớp phủ bề mặt đô thị của khu vực nghiên cứu, các loại hình che phủ bề mặt đất được chia thành các loại sau: bề mặt không thấm, đất trống, thực vật và mặt nước.

\subsubsection{Phương pháp GIS}

Thuật toán chồng xếp (Overlay) trong ArcMap được sử dụng trong nghiên cứu nhằm xác định mối quan hệ không gian giữa số liệu nhiệt độ bề mặt đô thị với các loại hình lớp phủ đô thị khi cùng được chiết tách từ một loại dữ liệu ảnh vệ tinh.

\section{Kết quả đạt được và thảo luận}

Hình 2 là kết quả phân loại lớp phủ đô thị khu vực quận 7, TP Hồ Chí Minh được chiết xuất từ ảnh vệ tinh Landsat 8 OLI. Hình 3 cho thấy kết quả của cơ cấu lớp phủ đô thị được tính theo ranh giới đến đơn vị các phường thuộc khu vực nghiên cứu. Hình 4 đã thể hiện rõ có sự khác nhau rõ rệt về cơ cấu lớp phủ đô thị, có những phường gần như bê tông hóa hoàn toàn (trên $80 \%$ là bề mặt không thấm). Để đánh giá độ chính xác của kết quả phân loại lớp phủ được chiết xuất từ ảnh Landsat 8 , chúng tôi đã lấy mẫu ngẫu nhiên từ kết quả phân loại và sử dụng dữ liệu ảnh Ikonos có độ phân giải không gian $1 \mathrm{~m}$ để xác định độ chính xác tập mẫu ngẫu nhiên. Độ chính xác tổng thể và hệ số Kappa được quan sát lần lượt là 88,4\% và 0,91\% cho kết quả phân loại hiện trạng lớp phủ đô thị năm 2017. Thêm vào đó, chúng tôi đã tự kiểm tra và sửa đổi kết quả phân loại trong ArcMap. Hình 3 cho thấy kết quả phân bố LST được tính toán từ kênh hồng ngoại nhiệt (kênh 10) ảnh Landsat 8 năm 2017. Kết quả thể hiện trên bản đồ LST cho thấy nhiệt độ của khu vực trung tâm, những nơi tập trung các khu công nghiệp, cảng chế xuất, khu dân cư cao hơn đáng kể so với một số khu vực ngoại thành. Khu vực có nhiệt độ cao chủ yếu tập trung ở các khu vực tập trung lớn các bề mặt không thấm, xây dựng đô thị và đường giao thông trong trung tâm thành phố, bao gồm khu dân cư, khu thương mại sầm uất và khu công nghiệp. Những khu vực này chủ yếu bao gồm các vật liệu không thấm nước như kim loại, nhựa đường và xi măng. Ngược lại, LST tương ứng với mặt nước, công viên, đất xanh và đất trồng trọt tương đối thấp. Sự tương phản đáng kể giữa nhiệt độ đô thị và ngoại ô cho thấy sự tồn tại của hiện tượng đảo nhiệt đô thị nổi bật.

Dựa trên các giá trị thể hiện trên Hình 4 về cơ cấu lớp phủ đô thị, Hình 5 thể hiện biểu đồ hiển thị 


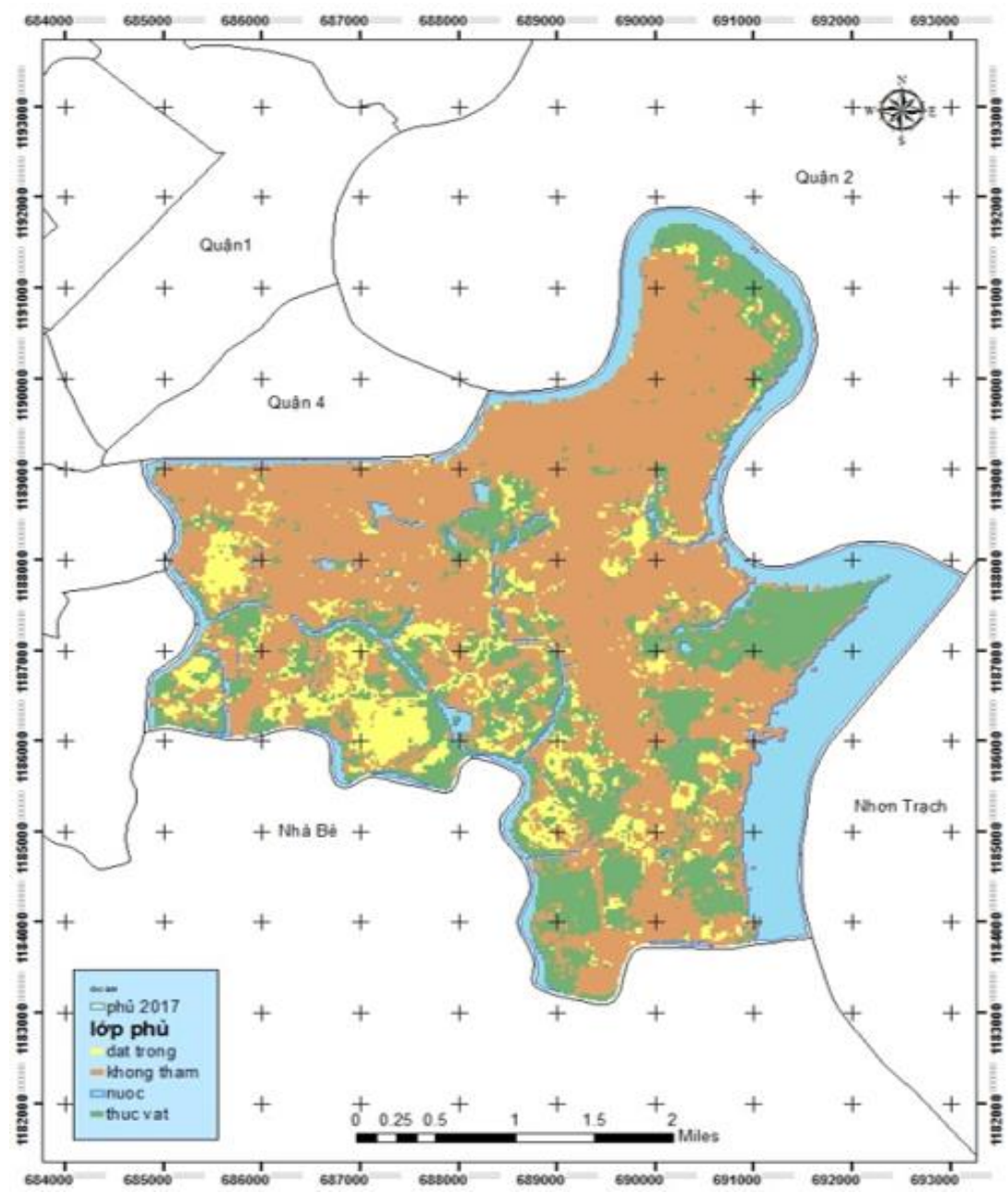

Hình 2. Hiện trạng phân bố lóp phủ đô thị khu vực Quận 7, TP HCM.

nhiệt độ bề mặt từng phường và các số liệu thống kê về nhiệt độ bề mặt (trung bình, thấp nhất, cao nhất) và cơ cấu lớp phủ của từng phường trong khu vực Quận 7, TP Hồ Chí Minh năm 2017 (Bảng 1), chúng ta có thể thấy quá trình quy hoạch đô thị cần phải có sự cân bằng về phân bổ các đối tượng lớp phủ trong khu vực đô thị, với những khu vực có nhiều lớp phủ xanh và mặt nước thì nhiệt độ khu vực ấy sẽ thấp hơn so với khu vực tập trung mật độ các lớp phủ không thấm. Cụ thể, chúng ta sẽ xem xét mối quan hệ giữa nhiệt độ bề mặt và cơ cấu lớp phủ đô thị của khu vực quận 7 TP Hồ Chí Minh như sau:

- Phường Tân Kiểng, Tân Quy và Tân Thuận Tây: nhiệt độ bề mặt của khu vực này được thấy là cao nhất với trị đo nhiệt trung bình lần lượt là: $31,76^{\circ} \mathrm{C}, 31,45^{\circ} \mathrm{C}$ và $31,9^{\circ} \mathrm{C}$ tương ứng với cơ cấu lớp phủ bề mặt được xác định trên $80 \%$ bề mặt lớp phủ là khu vực không thấm, trong đó tỷ lệ phần trăm của mặt nước và thực vật chiếm rất nhỏ trong tổng diện tích của ba phường .

- Phường Bình Thuận, Tân Hưng, Tân Phú, Tân Phong và Tân Thuận Đông: nhiệt độ bề mặt của các phường này được thấy là tương đối cao, biến thiên từ $30,44^{\circ} \mathrm{C}$ đến $30,9^{\circ} \mathrm{C}$ tương ứng với cơ cấu lớp phủ bề mặt được xác định trên $50 \%$ bề mặt lớp phủ là khu vực không thấm và đất trống, trong đó tỷ lệ phần trăm của mặt nước và thực vật chưa cao.

- Phường Phú Thuận và Phú Mỹ: là hai phường có giá trị nhiệt độ bề mặt được xác định là thấp nhất $29,1^{\circ} \mathrm{C}$ và $29,5^{\circ} \mathrm{C}$. Xét về cơ cấu lớp phủ bề mặt của hai phường này lần lược được xác định dưới 50\% bề mặt lớp phủ là khu vực không thấm và đất trống, trong đó tỷ lệ phần trăm của mặt nước và thực vật chiếm $50 \%$ so với tổng diện tích của hai phường. Hình 6 thể hiện kết quả chồng xếp giữa hiện trạng phân bố nhiệt bề mặt và hiện 


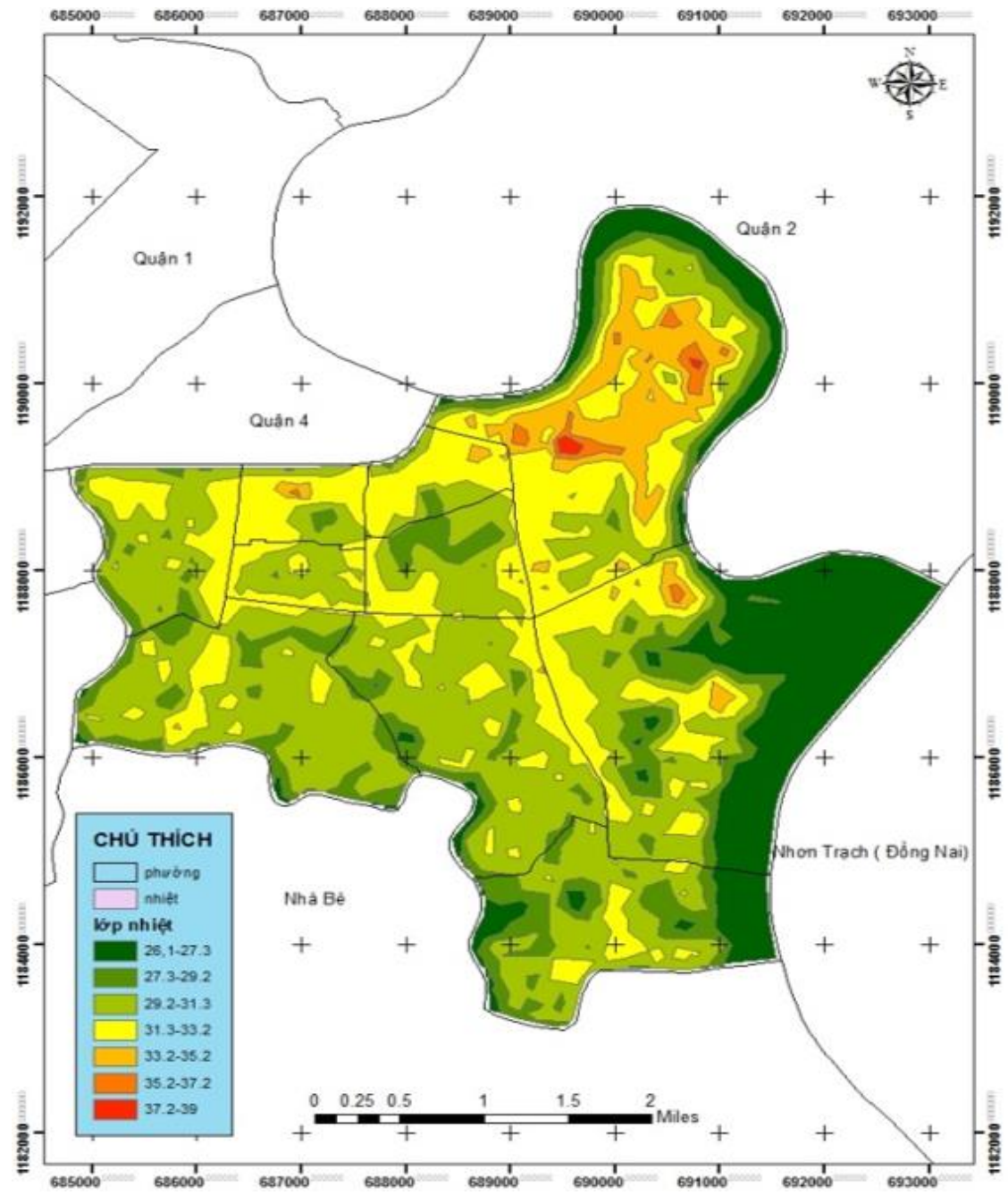

Hình 3. Hiện trạng phân bố nhiệt độ bề mặt khu vực Quận 7, TP HCM.

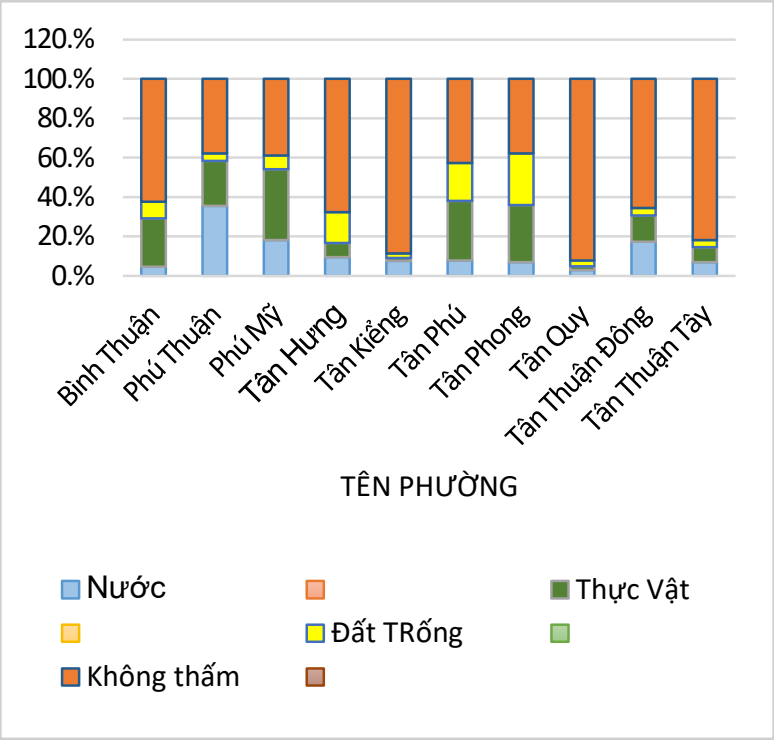

Hình 4. Cơ cấu hiện trạng lóp phủ đô thị khu vực Quận 7, TP HCM năm 2017.

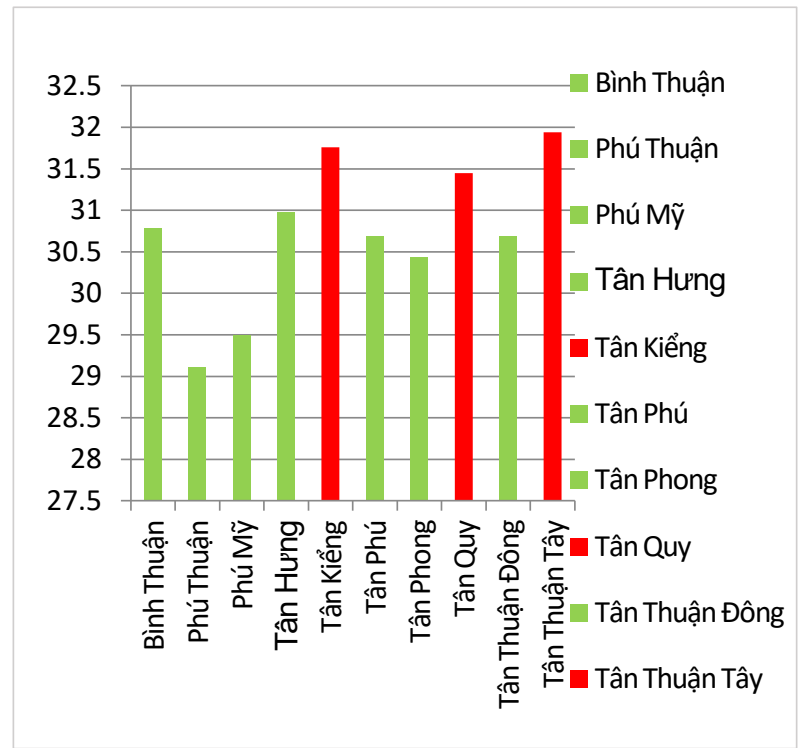

Hình 5. Biểu đồ hiển thị nhiệt độ bề mặt từng phường khu vực Quận 7, TP HCM năm 2017. 
Bảng 1. Dũ liệu thống kê cơ cấu phân bố lớp phủ bề mặt và giá trị nhiệt độ năm 2017 khu vực quận 7, TP Hồ Chí Minh.

\begin{tabular}{|c|c|c|c|c|c|c|c|c|c|}
\hline TT & Tên phường & Thấp nhất & Cao nhất & Trung bình & Không thấm & Đất trống & Nước & Thực vật & Tổng \\
\hline 1 & Bình Thuận & 27,86 & 32,91 & 30,79 & 62,52 & 8,36 & 4,50 & 24,62 & 100 \\
\hline 2 & Phú Thuận & 26,27 & 36,06 & 29,11 & 37,77 & 3,96 & 35,52 & 22,75 & 100 \\
\hline 3 & Phú Mỹ & 26,43 & 32,88 & 29,50 & 39,01 & 6,83 & 18,14 & 36,02 & 100 \\
\hline 4 & Tân Hưng & 27,89 & 33,64 & 30,98 & 67,79 & 15,70 & 9,50 & 7,02 & 100 \\
\hline 5 & Tân Kiểng & 28,11 & 35,90 & 31,76 & 88,59 & 2,32 & 7,46 & 1,63 & 100 \\
\hline 6 & Tân Phú & 27,00 & 33,76 & 30,69 & 42,82 & 19,15 & 7,74 & 30,30 & 100 \\
\hline 7 & Tân Phong & 27,18 & 33,72 & 30,44 & 37,80 & 24,40 & 6,88 & 28,92 & 100 \\
\hline 8 & Tân Quy & 29,49 & 33,25 & 31,45 & 87,80 & 2,02 & 6,79 & 3,38 & 100 \\
\hline 9 & Tân Thuận Đông & 26,62 & 38,62 & 30,69 & 65,70 & 3,68 & 17,26 & 13,36 & 100 \\
\hline 10 & Tân Thuận Tây & 28,20 & 34,17 & 31,94 & 81,82 & 3,71 & 6,91 & 7,57 & 100 \\
\hline
\end{tabular}

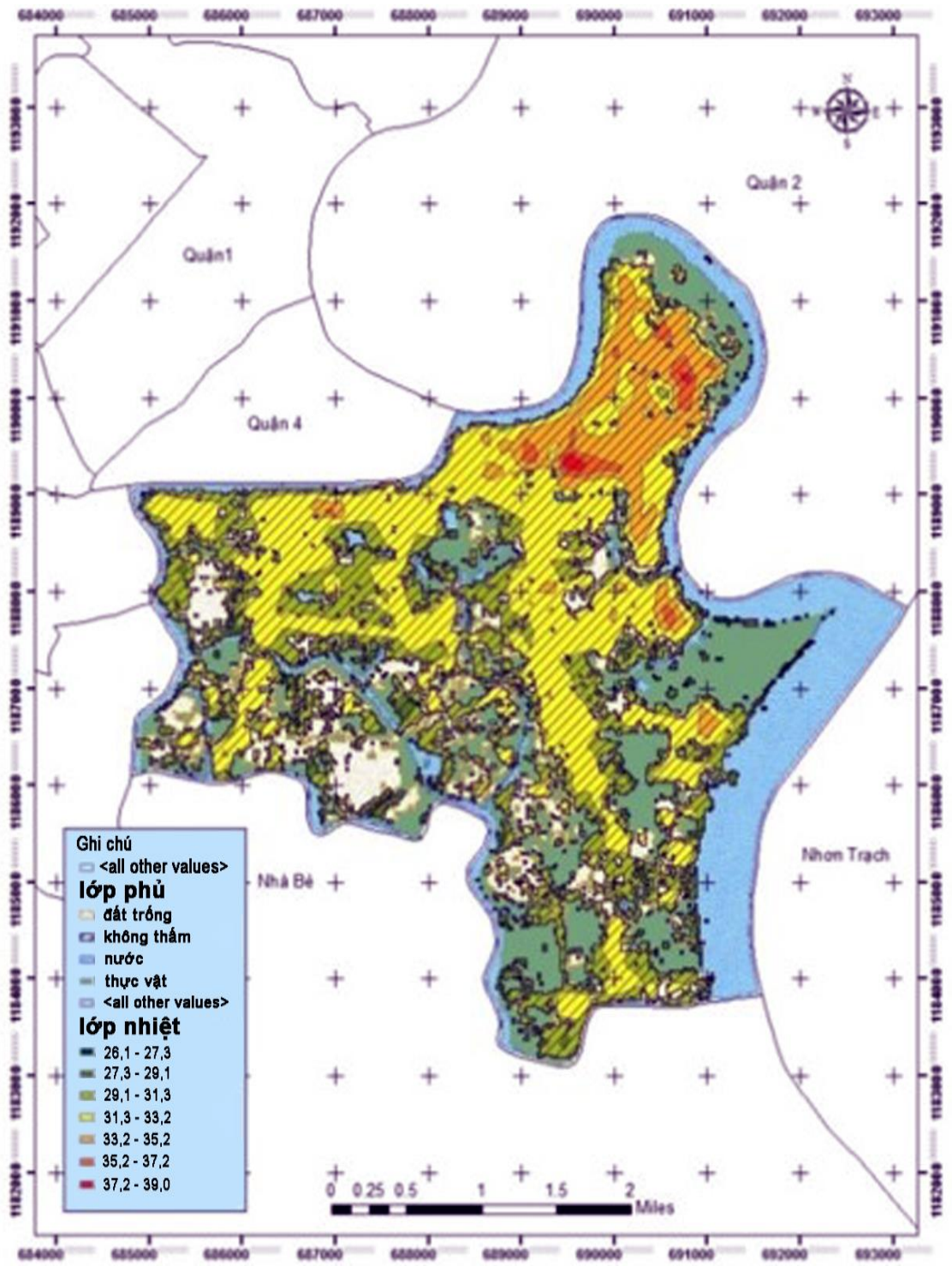

Hình 6. Kết quả chồng xếp giữa hiện trạng lớp phủ bề mặt đô thị với hiện trạng phân bố nhiệt khu vực nghiên cúu. 
trạng phân loại lớp phủ đô thị khu vực nghiên cứu năm 2017. Kết quả nghiên cứu cũng cho thấy, các khu vực có nhiệt độ cao tương ứng với các lớp phủ dân cư và đất trống, còn các khu vực có lớp phủ là thực vật và mặt nước là những nơi có giá trị nhiệt độ bề mặt được xác định là có giá trị nhỏ nhất.

Như vậy, kết quả của nghiên cứu này cũng cho thấy, trong khu vực quận 7 , nhiệt độ bề mặt xác định được của từng phường có giá trị khác nhau và có mối quan hệ thuận giữa phần trăm lớp phủ không thấm và đất trống với giá trị nhiệt độ bề mặt được xác định từ kênh ảnh hồng ngoại nhiệt Landsat. Kết quả nghiên cứu cho thấy, để có không gian sống đô thị cùng môi trường nhiệt độ phù hợp với cuộc sống của con người thì cơ cấu phân bổ lớp phủ bề mặt đô thị nên là: $50 \%$ bề mặt không thấm và đất trống và $50 \%$ còn lại là mặt nước và thực vật.

\section{Kết luận và kiến nghị}

Dựa trên tư liệu ảnh Landsat 8 OLI của khu vực Quận 7 TP Hồ Chí Minh, nghiên cứu này đã trích xuất thông tin về lớp phủ bề mặt đô thị, hiện trạng phân bố nhiệt LST và đã chỉ ra được cấu trúc lớp phủ bề mặt đô thị để đạt được chỉ số LST phù hợp với môi trường sống của dân cư trong đô thị.

Nghiên cứu này đã chỉ ra được hai kết luận quan trọng sau: (1) Khu vực quận 7, TP. Hồ Chí Minh cần thiết phải ngăn chặn UHI, đặc biệt trong mùa hè và cần giảm sự khác biệt LST giữa các vùng khác nhau. Những khác biệt này đóng vai trò quan trọng trong việc hình thành các đảo nhiệt trong đô thị. (2) Ở những khu vực có độ che phủ xanh thấp ( $<10 \%$ ), với tỷ lệ đơn vị diện tích đất không thấm quá lớn $(\geq 80 \%)$ có thể tạo ra sức nóng đáng kể cho những khu vực đô thị dày đặc, do đó, cần tăng những mảng lớp phủ thực vật để làm giảm bức xạ nhiệt đô thị một cách hiệu quả hơn.

Ứng dụng tư liệu viễn thám hồng ngoại nhiệt Landsat và công cụ phân tích không gian trên GIS cho phép thấy rõ mối quan hệ giữa cơ cấu lớp phủ bề mặt đô thị với giá trị nhiệt độ bề mặt trong khu vực đô thị. Kết quả nghiên cứu cho thấy UHI bị ảnh hưởng trực tiếp từ việc phân bổ cơ cấu lớp phủ giữa các khu vực trong đô thị là khác nhau. UHI gây ra những tác động tiêu cực ảnh hưởng đến chất lượng cuộc sống trong môi trường đô thị cho chính dân cư sống trong đó.

Từ các kết quả trên, nghiên cứu xin đưa ra kiến nghị với các nhà quy hoạch đô thị đó là cần phải có cơ cấu phân bổ lớp phủ đô thị hợp lý nhằm giảm nhẹ sự gia tăng nhiệt độ trong quá trình đô thị hóa, hướng tới phát triển đô thị bền vững và sinh thái.

\section{Lòi cảm ơn}

Tập thể tác giả xin chân thành cảm ơn sự hỗ trợ của đề tài: Ứng dụng công nghệ viễn thám và GIS nghiên cứu hiện tượng đảo nhiệt đô thị khu vực thành phố Hồ Chí Minh. Mã số: T19 - 44.

\section{Tài liệu tham khảo}

Buyantuyev, A., Wu, J., (2010). Urban heat islands and landscape heterogeneity: linking spatiotemporal variations in surface temperatures to land - cover and socioeconomic patterns. Landscape Ecology $25.17-33$.

Chen, X. L., Zhao, H. M., Li, P. X., Yin, Z. Y., (2006). Remote sensing image - based analysis of the relationship between urban heat island and land use/cover changes. Remote Sensing of Environment, 104. 133 - 146.

Environmental Protection Agency's Office of Atmospheric Programs (EPA) (2008). Reducing Urban Heat Islands: Compendium of Strategies Urban Heat Island Basics.

Grimmond Sue, (2007). Urbanization and global environmental change: local efects of urban warming. Geographical Journal, 173. 83 - 88.

Kato, S., Yamaguchi, Y., (2005). Analysis of urban heat - island efect using ASTER and ETM + Data: separation of anthropogenic heat discharge and natural heat radiation from sensible heat fux. Remote Sensing of Environment, 99. 44 - 54.

Liu, K., Zhang, X., Li, X., Jiang, H., (2014). Multiscale Analysis of Urban Thermal Characteristics: Case Study of Shijiazhuang, China. Journal of applied remote sensing. 16 - 28.

Liu, K., Su, H., Li, X., Wang, W., Yang, L., Liang, H., (2016). Quantifying Spatial - Temporal Pattern of Urban Heat Island in Beijing: An Improved Assessment Using Land Surface Temperature (LST) Time Series Observations From LANDSAT, MODIS, and Chinese New Satellite GaoFen - 1.Journal of Selected Topics in Applied 
Earth Observations and Remote Sensing 9, 2028 - 2042.

Schwarz, N., Lautenbach, S., Seppelt, R., (2011). Exploring indicators for quantifying sur - face urban heat islands of European cities with MODIS land surface temperatures. Remote Sensing of Environment 115. 3175 - 3186.

Tran Hung, Uchihama, D., Ochi, S., Yasuoka, Y., (2006). Assessment with satellite data of the urban heat island efects in Asian mega cities. International Journal of Applied Earth Observation and Geoinformation 8. 34 - 48.

Udhi C. Nugroho and Dede Dirgahayu Domiri, (2015). Identification of land surface temperature distribution of geothermal area in Ungaran mount by using landsat 8 imagary, International Journal of Remote Sensing and Earth Sciences 12.

United Nations, (2008). World urbanization prospects: The 2007 revision. New York.

Voogt, J. A., (2002). Urban heat island. In I. Douglas (Ed.), Causes and consequences of global environmental change, Chichester: John Wiley \& Sons Ltd 3.660 - 666.

Voogt, J. A., \& Oke, T. R. (2003). Thermal remote sensing of urban climates. Remote Sensing of Environment 86(3). 370 - 384.
Weimin Wang, Kai Liu, Rong Tang, Shudong Wang, (2019). Remote sensing image - based analysis of the urban heat island efect in $\mathrm{T}$ Shenzhen, China. Physics and Chemistry of the Earth 110. 168 - 175.

Weng, Q., (2009). Thermal infrared remote sensing for urban climate and environmental studies: methods, applications, and trends. ISPRS J. Photogrammetry Remote Sensing 64. 335 - 344.

Weng, Q., Lu, D., Schubring, J., (2004). Estimation of land surface temperature - vegetation abundance relationship for urban heat island studies. Remote Sensing of Environment 89. 467 - 548.

Weng, Q., Lu, D., (2008). A sub - pixel analysis of urbanization efect on land surface tem perature and its interplay with impervious surface and vegetation coverage in Indianapolis, United States. International Journal of Applied Earth Observation and Geoinformation 10.68 - 83.

Yuan, F., Bauer, M. E., (2007). Comparison of impervious surface area and normalized diference vegetation index as indicators of surface urban heat island efects in Landsat imagery. Remote Sensing of Environment 106. 375 - 386. 